\title{
Assessing the measurement of airway resistance by the interrupter technique
}

\author{
Yolanda Zuriarrain Reyna, M.D., ${ }^{a}$ Alejandro López Neyra, B.S., \\ Verónica Sanz Santiago, B.S., ${ }^{a}$ Esmeralda Almería Gil, Nurse, ${ }^{a}$ and \\ José Ramón Villa Asensi, B.S. ${ }^{a}$
}

\begin{abstract}
Introduction. Pulmonary function tests allow an objective assessment of the degree of bronchial obstruction in collaborative subjects. The measurement of airway resistance using passive methods is very helpful in non-collaborative subjects. The objective of this study was to assess the applicability of measuring airway resistance by the interrupter technique (Rint) in pediatric subjects, determining its reproducibility, reliability and accuracy versus other techniques
\end{abstract} to measure airway resistance.

Material and Methods. Cross-sectional study in healthy children and in children with an obstructive airway disease, all aged 2-18 years old. The Rint was measured using a portable device and results were compared to airway resistance measured by oscillometry and plethysmography. The reproducibility of measurements and the influence of the different outcome measures (use of mask or mouthpiece, cheek support, or nose clip) were assessed.

Results. Valid measurements were obtained in $82.6 \%$ of 460 children ( $47.6 \%$ younger than 7 years old). Reproducibility was very good (ICC $=0.9412 ; \mathrm{p}<0.00001$ ), and no differences were found among the measurements obtained at separate time intervals $(0.75 \pm 0.3$ versus $0.74 \pm 0.28 ; p=0.435)$. None of the factors indicated before had an effect on the reproducibility of measurements. Resistance values obtained by plethysmography and oscillometry were higher than those obtained using the Rint, with a positive correlation between them. The higher the degree of airway obstruction, the worse the correlation with plethysmography.

Conclusions. The Rint measurement is a plausible and reproducible technique, and has an adequate correlation with the resistance measurements obtained using oscillometry or plethysmography, thus making it useful for noncollaborative patients. In patients with airway obstruction, this technique could underestimate resistance, so it would be a hurdle to use it to follow-up subjects with a moderate to severe obstructive disease or in bronchial challenge tests. Key words: airway resistance, Rint, pulmonary function, assessment study, pediatric age.

http:/ /dx.doi.org/10.5546/aap.2013.495

\section{INTRODUCTION}

Forced spirometry is the gold standard pulmonary function used in children and adults. ${ }^{1}$ Its most significant limitation is that it requires the patient to collaborate, thus making it difficult to be used in children younger than 6 years old. In spite of this, there are standards for having forced spirometries performed in children $<5$ years old ${ }^{2}$ and reference values have been established for children as of 3 years old. ${ }^{3}$ There are other methods for the assessment of airway resistance that do not require excessive collaboration, such as plethysmography or impulse oscillometry (IOS), but they have to be performed using complex devices that are not available in all sites.

The measurement of airway resistance by the interrupter technique (Rint) is simple, it requires minimum collaboration and can be done with a small portable device. There are reference Rint values for children, showing a reverse correlation with height and age. ${ }^{4-8}$ However, its use has still not expanded, probably because it has not been sufficiently assessed.

In 1927, it was proposed to estimate alveolar pressure (Palv) by performing a rapid occlusion of the airways during the respiratory cycle at rest, ${ }^{9}$ assuming that Palv would equal mouth pressure (Pmo)..$^{10}$ Studies using this technique were resumed in the $1970 \mathrm{~s}^{11}$ and have continued to date, ${ }^{12}$ basically due to the technical advances made with interrupters and signal treatment. ${ }^{13,14}$

The European Respiratory Society (ERS) and the American Thoracic Society (ATS) have established standardized guidelines for the measurement of the mechanical properties of the respiratory system using occlusion techniques. ${ }^{15}$ 
The hypothesis posed in this study is that the Rint, versus forced spirometry, can be applied in children at even younger ages. A generalized use of the Rint could improve the assessment of obstructive respiratory diseases in pediatric subjects.

The main objective of this study was to assess the applicability of the Rint in pediatric subjects, determining its reproducibility, reliability and accuracy versus other techniques to measure airway resistance. The secondary objective was to assess the possible influence on the Rint measurement of outcomes, such as using a mask, a mouthpiece, cheek support, or a nose clip.

\section{MATERIAL AND METHODS}

This was a cross-sectional study conducted in a healthy population and in a population with obstructive respiratory disease, all aged between 2 and 18 years old. Healthy subjects were recruited from a municipal sports center (Las Rozas, Spain) through a letter explaining the study and an ad posted on the notice board. Patients with an obstructive respiratory disease were recruited from the Pediatric Pulmonology

Figure 1. Patient and examiner positioning to measure airway resistance using the interrupter technique. Observe how the examiner's hands support the patient's cheeks and the floor of the mouth

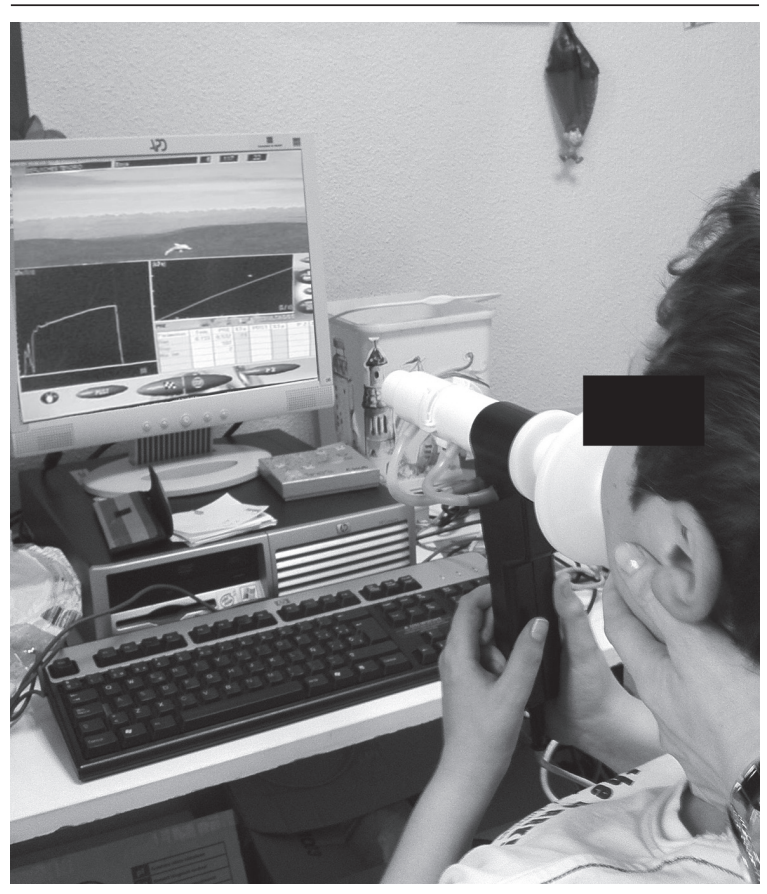

outpatient offices. All subjects, or their parents or legal guardians, were asked to sign an informed consent. The study protocol was approved by the local Ethics and Clinical Research Committee.

In the subset of healthy subjects, those with a history of chronic cardiorespiratory disease were excluded. In both subsets, subjects with an acute respiratory condition in the past three weeks were excluded. Subjects with rhinitis or eczema, and those exposed to second-hand smoking were not excluded. ${ }^{16}$

A pneumotachograph with an occluder that interrupts airway flow is required for the Rint measurement. In this study, a portable Spirodyn'R device provided by Dyn'R Aixen-Provence (France) was employed, with a disposable bacterial filter attached. The measurement is performed with the subject sitting down and breathing at rest through a mouthpiece with the nose blocked, or through a mask with a mouthpiece. ${ }^{14}$ Any air leak through the mouth must be avoided and the subject's cheeks and the floor of the mouth have to be firmly supported to obtain a correct Pmo measurement (Figure 1). Once breathing is stabilized, the pneumotachograph is rapidly and completely closed for 100 milliseconds (ms). It takes approximately $40 \mathrm{~ms}$ for the Palv and the Pmo to balance, although time may vary depending on the degree of airway obstruction. ${ }^{17}$

At the beginning of the occlusion, a rapid increase in mouth pressure is followed by marked oscillations due to the upper airway compliance, which lasts approximately $30-40 \mathrm{~ms} .{ }^{18}$ Then follows a second phase with no oscillations when pressure is stabilized and the signal turns more linear until the airway is opened again (Figure 2). The estimated resistance will vary depending on the point at which the pressure is measured. ${ }^{19}$

The Rint measurement using a linear backextrapolation algorithm is at present the most commonly used method. ${ }^{18}$ The expiratory flow and mouth pressure (Pmo) are measured immediately before the interruption starts. The interruption pressure (Pint) is the pressure measured at the time of the interruption in the linear back-extrapolation of the pressure curve (see Figure 2). The Rint is calculated by dividing the pressure change (Pint-Pmo) by the flow immediately before occlusion. The device estimates the Rint during exhalation using the two methods of analysis described by Phagoo..$^{20,21}$ In this study, the only method used was the linear back-extrapolation. 
Measurements were performed in the sports center (healthy subjects) and in the pulmonary function laboratory of the Pulmonology Division (subjects with a respiratory disease). The same person was in charge of obtaining the measurements in accordance with the ATS/ ERS recommendations. ${ }^{15}$ Seven acceptable measurements were obtained from each subject, and the mean value was considered the Rint value. An acceptable measurement was that obtained in the following conditions: no leaks around the mask or mouthpiece, the pressure increases rapidly following occlusion maintaining a plateau for at least 1 second, there is no flow through the pneumotachograph during occlusion, no increased pressure due to respiratory efforts during and after occlusion, and the expiratory volume is at least $80 \%$ of the previous expiratory volume. In addition, it was required that the dispersion of measurements had to be lower than or equal to $20 \% .^{22}$

In a group of patients, the Rint was measured on two different occasions so as to assess the measurement reproducibility. Measurements were obtained using a mouthpiece, a nose clip and cheek support, and with none of these to assess their potential influence on the measurement.

FIGURE 2. Pressure curve produced during the interruption over time to measure resistance using the linear backextrapolation interrupter technique. Time zero (T0) is the moment that coincides with the maximum peak pressure (Peak Pres) and the interruption time (Tint), T0 + $15 \mathrm{~ms}$. The pressure curve slope is calculated considering T30 (T0 $+30 \mathrm{~ms})$ and $\mathrm{T70}(\mathrm{T0}+70 \mathrm{~ms})$ and the pressure values in these two points (P30 and P70), using the following formula: (P70-P30)/(T70-T30). The interruption pressure (Pint) is the pressure measured at the Tint in the linear back-extrapolation of the pressure curve

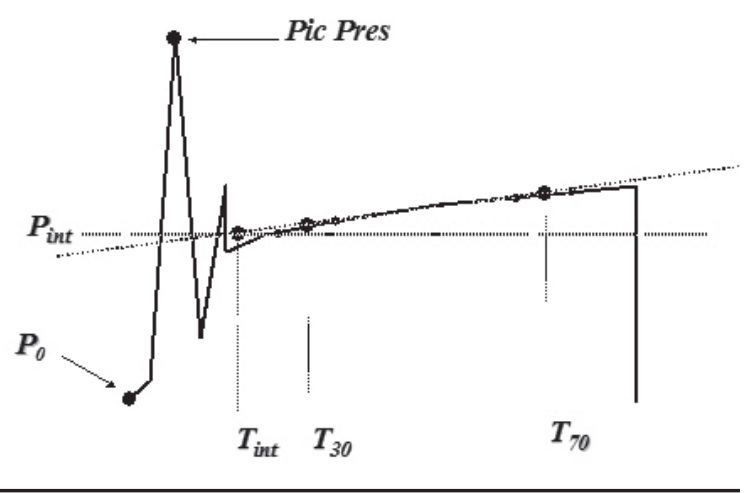

The Rint measurement was compared to the resistance measurements obtained using a plethysmography and IOS in subjects with a respiratory disease who had also undergone a forced spirometry. These tests were performed in the pulmonary function laboratory with the Master Screen (Jaeger, Germany) system, which was calibrated on a daily basis and in compliance with the ATS/ERS standards. ${ }^{1,2}$ The Rint and IOS measurements were obtained before spirometry to avoid any potential change in the airway smooth muscle tone. ${ }^{23}$

The statistical analysis was done using the SPSS software, version 12.0 (SPSS lnc, Chicago, USA). Quantitative outcome measures were compared using the Student's t test for independent samples and related samples. The relationship between quantitative outcome measures and their relative significance was determined with a multivariate analysis using a binary logistic regression. The reproducibility of Rint measurements was assessed using the intraclass correlation coefficient (ICC) ${ }^{24}$

A value of $\mathrm{p} \leq 0.05$ was considered significant.

\section{RESULTS}

A total of 460 children aged 2-18 years old were recruited, 244 (53\%) males, 219 (47.6\%) younger than 7 years old, and $263(53.9 \%)$ with an obstructive respiratory disease. The demographic data (mean \pm standard deviation) were: age 8.06 \pm 3.62 years old (range: $2-18.5$ ), height $128 \pm 20.57$ $\mathrm{cm}$ (range: 85-181), and weight $30.52 \pm 13.47 \mathrm{~kg}$ (range: 10-87). The subjects in the group with a respiratory disease were older $(8.52 \pm 3.57$ versus $6.43 \pm 3.45$ years old; $p<0.001)$, heavier $(33.34 \pm$ 12.56 versus $26.65 \pm 13.75 \mathrm{~kg}$; $\mathrm{p}<0.001$ ) and taller $(133.75 \pm 18.66$ versus $121.09 \pm 20.87 \mathrm{~cm} ; \mathrm{p}<0.001)$ than those in the healthy group.

Acceptable Rint measurements were obtained in 380 children $(82.6 \%)$. The reasons for not accepting the measurement were lack of collaboration (5 children) and dispersion of measurements $>20 \%$ (75 children). Specific percentages of acceptable measurements per age group are shown in Table 1 . The multivariate analysis showed that factors influencing the validity of measurement are age (OR: 1.283; CI: $1.15-1.42 ; \mathrm{p}<0.0001)$ and having a disease (OR: 7.818; CI: 4-15.26; $\mathrm{p}<0.0001$ ). Gender was not a determining factor of test validity $(\mathrm{p}=0.397)$. The dispersion of measurements has a non-linear correlation with age, showing a reduction up to 5 years old and remaining below $20 \%$ as of this age. 
The measurement was repeated at 5 minutes in 208 children (60 healthy subjects, 148 with stable asthma; mean age: $7.52 \pm 3.39$ years old, range: 2-17 years old) to assess reproducibility, and acceptable measurements were obtained in $155(74.5 \%)$ of them. No differences were observed between both Rint values $(0.75 \pm 0.3$ versus $0.74 \pm 0.28 ; \mathrm{p}=0.435)$ or in the dispersion $(13.07 \pm 4.95 \%$ versus $13.47 \pm 5.22 \% ; p=0.298)$. The linear correlation among measurements $(r=0.891$, $\left.\mathrm{r}^{2}=0.794 ; \mathrm{p}<0.0001\right)$, and the intraclass correlation coefficient (ICC $=0.9412$; 95\% CI: 0.9193-0.9572; p $<0.00001$ ) were very high.

Fifty children with stable asthma (mean age: $8.07 \pm 2.44$ years old; range: $2-13$ years old) were divided into three subsets to study how providing cheek support (35 children, 30 acceptable measurements), using a mouthpiece of mask (25 children, 19 acceptable measurements), and using a nose clip (15 children, 13 acceptable measurements) influenced measurements. The reproducibility of measurements with these elements and without them was excellent; no differences were observed in measurements (Table 2 ), although the Rint correlation with the forced expiratory volume in 1 second (FEV1) was better with a mouthpiece $(\mathrm{r}=-0.732)$ and cheek support $(r=0.691)$ than with a mask $(r=-0.586)$.

A total of 112 subjects (mean age: $9.57 \pm 3.5$ years old; range: $4-17$ years old) with obstructive respiratory disease ( 88 with asthma, 22 with cystic fibrosis, and 9 with other conditions) and acceptable Rint measurements were also subjected to forced spirometry, plethysmography and IOS, and acceptable measurements were obtained in 107, 65 and 95 subjects, respectively.

TABLE 1. Number of acceptable and non acceptable resistance measurements obtained with the interrupter technique by age

\begin{tabular}{|c|c|c|c|c|}
\hline Age (years) & $\mathbf{n}$ & Non acceptable & Acceptable & $\begin{array}{l}\text { Percentage of } \\
\text { acceptable measurements }\end{array}$ \\
\hline 2 & 17 & 15 & 2 & 11.8 \\
\hline 3 & 32 & 11 & 21 & 65.6 \\
\hline 4 & 42 & 16 & 26 & 61.9 \\
\hline 5 & 72 & 10 & 62 & 86.1 \\
\hline 6 & 56 & 8 & 48 & 85.7 \\
\hline Total $<7$ & 219 & 60 & 159 & 72.6 \\
\hline 7 & 39 & 3 & 36 & 92.3 \\
\hline 8 & 40 & 8 & 32 & 80 \\
\hline 9 & 30 & 2 & 28 & 93.3 \\
\hline 10 & 17 & 2 & 15 & 88.2 \\
\hline 11 & 35 & 1 & 34 & 97.1 \\
\hline 12 & 24 & 1 & 23 & 95.8 \\
\hline 13 & 21 & 3 & 18 & 85.7 \\
\hline 14 & 13 & - & 13 & 100 \\
\hline 15 & 10 & - & 10 & 100 \\
\hline 16 & 4 & - & 4 & 100 \\
\hline 17 & 5 & - & 5 & 100 \\
\hline 18 & 3 & - & 3 & 100 \\
\hline Total $\geq 7$ & 241 & 20 & 221 & 91.7 \\
\hline Total & 460 & 80 & 380 & 82.6 \\
\hline
\end{tabular}

TABLE 2. Comparison of values obtained in the measurement of resistance using the interrupter technique (Rint) according to the technique of measurement used

\begin{tabular}{lccc}
\hline & $\begin{array}{c}\text { Rint } \\
\text { Mouthpiece or } \\
\text { mask }(n=25)\end{array}$ & $\begin{array}{c}\text { Rint } \\
\text { With and without } \\
\text { cheek support }(n=35)\end{array}$ & $\begin{array}{c}\text { Rint } \\
\text { and without } \\
\text { nose clip }(n=15)\end{array}$ \\
\hline Acceptable measurements & 19 & 30 & 13 \\
Linear correlation & $r=0.889$ & $r=0.875$ & 0.963 \\
ICC & 0.9408 & 0.9324 & 0.9811 \\
\hline
\end{tabular}

${ }^{*} \mathrm{p}<0.01$ in all cases. $\mathrm{n}$ : number of measurements performed. ICC: intraclass correlation coefficient. 
Resistance values measured with each method were different from those obtained with the Rint technique, except for the effective resistance measured by plethysmography (Table 3). The correlation between the Rint and the rest of the resistance values was adequate; the best correlation was obtained with resistance values measured with the IOS (see Table 3).

The relationship between the Rint and plethysmography resistance measurements was assessed in 65 children based on the degree of obstruction. A weak correlation $\left(\mathrm{r}^{2}=0.203\right.$; $\mathrm{p}<0.0001$ ) was found between the difference of the Rint and plethysmography measurements and the degree of airway obstruction expressed as a percentage of the theoretical FEV1, (Figure $3)$; therefore, the lower the FEV1 the larger the difference.

\section{DISCUSSION}

This study demonstrates that the Rint measurement is a plausible method for the pediatric population. A large and representative sample of routine consultations with a healthy and a diseased population covering a wide age range was used in this study.

Many published studies have been done with a small sample size ( $<30$ patients), ${ }^{14,20,21}$ although there are a few studies with a larger population. ${ }^{4-7}$ In addition, most publications included children

TABLE 3. Differences and correlations between the interrupter technique and the rest of the resistance or obstruction measurements

\begin{tabular}{lllccc}
\hline & & & $\begin{array}{c}\text { Differenced } \\
\text { with the Rint }\end{array}$ & $\begin{array}{l}\text { Linear } \\
\text { correlation (r) }\end{array}$ \\
\hline Interrupter technique & Rint & $0.68 \pm 0.31 \mathrm{kPaL}^{-1} \mathrm{~s}$ & $\mathrm{~N} / \mathrm{A}$ & $\mathrm{N} / \mathrm{A}$ & $\mathrm{N} / \mathrm{A}$ \\
Impulse oscillometry & $\mathrm{Z} 5(n=95)$ & $0.88 \pm 0.33 \mathrm{kPaL}^{-1} \mathrm{~s}$ & $p<0.0001$ & 0.761 & $p<0.0001$ \\
& $\mathrm{R} 5(n=95)$ & $0.83 \pm 0.31 \mathrm{kPaL}^{-1} \mathrm{~s}$ & $p<0.0001$ & 0.749 & $p<0.0001$ \\
& $\mathrm{R} 20(n=95)$ & $0.57 \pm 0.16 \mathrm{kPaL}^{-1} \mathrm{~s}$ & $p<0.0001$ & 0.652 & $p<0.0001$ \\
Forced spirometry & $\mathrm{FEV}(n=107)$ & $1.82 \pm 0.67 \mathrm{~L}$ & $\mathrm{~N} / \mathrm{A}$ & -0.677 & $p<0.0001$ \\
& $\operatorname{MMEF}_{1}(n=107)$ & $1.86 \pm 0.88 \mathrm{~L} / \mathrm{s}$ & $\mathrm{N} / \mathrm{A}$ & 0.433 & $p<0.0001$ \\
Plethysmography & $\mathrm{FEV} / \mathrm{FVC}$ & $86.68 \pm 11.35 \%$ & $\mathrm{~N} / \mathrm{A}$ & 0.322 & $p<0.003$ \\
& $\operatorname{Rtot}_{1}(n=65)$ & $0.72 \pm 0.27 \mathrm{kPaL}^{-1} \mathrm{~s}$ & $p<0.0001$ & 0.73 & $p<0.0001$ \\
& $\operatorname{Reff}(n=65)$ & $0.64 \pm 0.25 \mathrm{kPaL}^{-1} \mathrm{~s}$ & $p=0.215$ & 0.657 & $p<0.0001$ \\
\hline
\end{tabular}

n: number of valid measurements in 112 patients; Rint: resistance measured by interrupter technique; $k P a:$ kilopascal; L: liter; s: second; Z5: impedance at $5 \mathrm{~Hz}$; R5 and R20: resistance at $5 \mathrm{~Hz}$ and $20 \mathrm{~Hz}$; FEV1: forced expiratory volume in 1 second; MMEF: expiratory flow between $25 \%$ and $75 \%$ of the forced vital capacity; Rtot: total resistance; Reff: effective resistance; N/A: not applicable.

FIGURE 3. Correlation between the difference of the resistance measured by plethysmography and the resistance measured by the interrupter technique (Rtot-Rint) and the degree of airway obstruction (expressed as a percentage of the theoretical forced expiratory volume in 1 second [FEV1])

Total sample

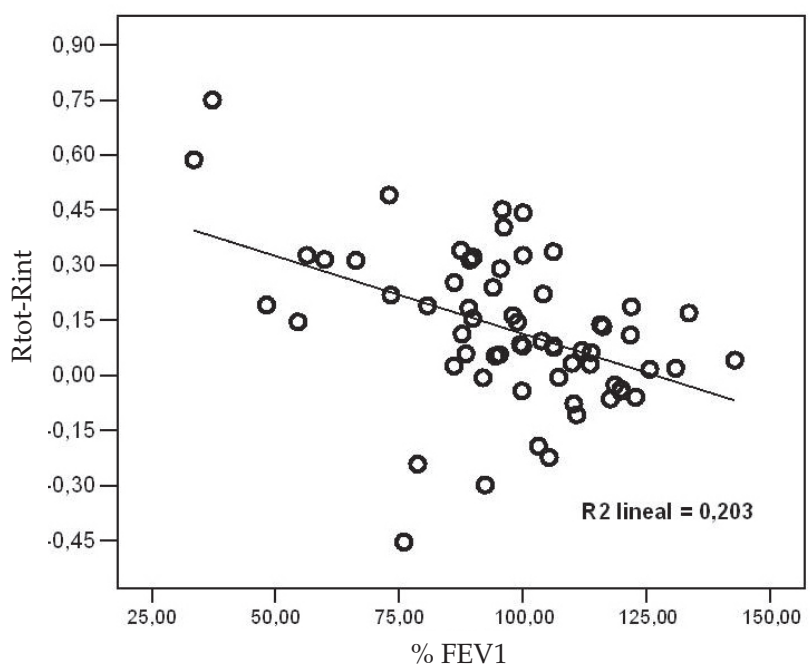


younger than 7 years old. The large number of children included in this study (460), both healthy and diseased, in addition to their wide age range (2-18 years old) make the observations obtained to be representative of the standard clinical practice.

Although the Rint measurement is easy to obtain, it should be noted that a single operator was in charge of the test, which may be a limitation at the time of considering outcomes in general.

The overall percentage of acceptable measurements was $82.6 \%(72.6 \%$ in children $<7$ years old, and $91.7 \%$ in children $>7$ years old), an intermediate value compared to published percentages (64-95\%). 4,5,25,26 The percentage of acceptable measurements obtained in children younger than 4 years old is remarkably lower than those published by other authors. ${ }^{4,25} \mathrm{An}$ explanation for this could be that authors did not provide details about which were the acceptability criteria for measurements. In this study, measurements were not considered acceptable if the dispersion was over $20 \%$, which may account for the lower number of acceptable values and the higher ICC in comparison to those published by these authors. Dispersion tends to stabilize at 5 years and older, so more acceptable measurements can be obtained as of this age.

Although, in theory, it is not necessary for patients to collaborate so as to measure the Rint, the fact is that it is difficult to obtain acceptable measurements in patients who are barely collaborative. $^{27}$

In relation to factors that can influence the validity of measurements, no significant influence was observed in relation to gender, but age and diagnosis did have an effect on it. These findings are logical and consistent with previous studies given that diseased children are more used to having pulmonary function tests performed.

In this study, seven measurements were done to each patient, obtaining a mean value and dispersion of measurements, because it has not been proven that more measurements would reduce the variation coefficient. ${ }^{28}$ Some authors prefer to use a median value instead of a mean value, ${ }^{29,30}$ but no consensus has been reached regarding whether results are best expressed using the mean or median value or even if it would be adequate to combine both. ${ }^{7}$

Few studies have dealt with shortterm reproducibility using large samples ${ }^{25,31}$ as in this study (208 children, 155 acceptable measurements). Some studies have assessed short-term reproducibility and variation over time, although with small samples. ${ }^{4,5,32}$ As with other previous studies, ${ }^{4,6,17-19,21,28}$ no significant differences were observed among measurements, indicating that the technique is adequately reliable, as the other techniques to measure resistances. ${ }^{26}$

One previous study ${ }^{33}$ found small differences in measurements obtained with a mouthpiece and a mask; for this reason, the mask was chosen, but did not improve reproducibility and it took longer to obtain each measurement. In our study, no significant differences were observed between both types of measurements, so it appears that there are no sufficient data to favor one method over the other. No differences were either found regarding the use of a nose clip or cheek support during the test. Data from previous studies are conflicting: some found differences between providing or not cheek support ${ }^{34}$ while others detected no differences at all. ${ }^{5}$

As the linear correlation and the ICC found between the Rint and the FEV1 are somewhat better with the use of a mouthpiece and cheek support, it would be preferable to obtain measurements this way whenever possible. However, these results are limited because of the small size of the studied groups. Studies conducted on larger samples are necessary in order to assess the need of all these measures.

The linear correlation values between the Rint and other measurements to detect airway obstruction demonstrates that this is a useful technique, and that results obtained are similar to those of other more commonly used pulmonary function tests. These values are similar to those obtained in other studies. ${ }^{13,18}$ However, resistance values are not exactly the same, so it is not recommended to make a direct comparison between the Rint and other measurements of airway resistance.

One of the possible limitations of the Rint is that, in patients with airway obstruction, the time of interruption may not be enough to equal Pmo and Palv, therefore yielding a value lower than the actual measurement. In this study, the difference between the Rint and the resistance measured by plethysmography was greater in patients with obstruction, with a linear correlation between the increase of such difference and the FEV1 drop. These results are similar to those published by other authors. ${ }^{4,17}$

The essential conclusion of this study is that the Rint measurement using a portable device is 
plausible and reproducible in children younger than 3 years old, with values quite similar to those obtained with a plethysmography or an IOS, although resistance may be underestimated in patients with airway obstruction. The recent finding of adequate reference values for our population allows the use of the Rint as an initial measurement in patients suspected of having an obstructive respiratory disease and in whom it is not possible to correctly perform a forced spirometry

\section{REFERENCES}

1. Miller MR, Hankinson J, Brusasco V, Burgos F, et al. Standardisation of spirometry. Eur Respir J 2005;26:319-38.

2. Beydon N, Davis SD, Lombardi E, Allen JL, et al. An official American Thoracic Society / European Respiratory Society statement: pulmonary function testing in preschool children. Am J Respir Crit Care Med 2007;175:1304-45.

3. Stanojevic S, Wade A, Cole TJ, Lum S, et al. Spirometry centile charts for young Caucasian children: the Asthma UK Collaborative Initiative. Am J Respir Crit Care Med 2009;180:547-52.

4. Merkus PJ, Mijnsbergen JY, Hop WC, de Jongste JC. Interrupter resistance in preschool children: measurement characteristics and reference values. Am J Respir Crit Care Med 2001;163:1350-5.

5. Lombardi E, Sly PD, Concutelli G, Novembre E, et al. Reference values of interrupter respiratory resistance in healthy preschool white children. Thorax 2001;56:691-5.

6. Merkus PJ, Arets HG, Joosten T, Siero A, et al. Measurements of interrupter resistance: reference values for children 3-13 yrs of age. Eur Respir J 2002;20:907-11.

7. Merkus PJ,Stocks J, Beydon N, Lombardi E, et al. Reference ranges for interrupter resistance technique: the Asthma UK Initiative. Eur Respir J 2010;36:157-63.

8. Li AM, Lam HS, So HK, Leung M, et al. Interrupter respiratory resistance in healthy Chinese preschool children. Chest 2009;136:554-60.

9. Neergaard K, Wirtz K. Die Massung der Str6mung swiderstande in den Atemwegen des Menschen, inbensondere bei Asthma und Emphysema. Z Klim Med 1927;105:51-82.

10. Respiratory mechanics in infants: physiologic evaluation in health and disease. American Thoracic Society / European Respiratory Society. Am Rev Respir Dis 1993;147:474-96.

11. Jackson AC, Milhorn HT Jr., Norman JR. A reevaluation of the interrupter technique for airway resistance measurement. J Appl Physiol 1974;36:264-8.

12. Carter ER. It is time to consider standardizing the interrupter technique. Eur Respir J 1997;10:1428-9.

13. Chowienczyk PJ, Lawson CP, Lane S, Johnson R, et al. A flow interruption device for measurement of airway resistance. Eur Respir J 1991;4:623-8.

14. Phagoo SB, Watson RA, Silverman M, Pride NB. Comparison of four methods of assessing airflow resistance before and after induced airway narrowing in normal subjects. J Appl Physiol 1995;79:518-25.

15. Gappa M, Colin AA, Goetz I, Stocks J. Passive respiratory mechanics: the occlusion techniques. Eur Respir J 2001;17:141-8.

16. Dezateux C, Wade A,Schmalisch G, Landau L. Maximizing effective research in infant respiratory function. In: Stocks J, Sly PD, Tepper RS, editors. Infant respiratory function testing. New York: Wiley-Liss; 1996. Págs.521-50.

17. Oswald-Mammosser M, Charloux A, Donato L, Albrech $\mathrm{C}$, et al. Interrupter technique versus plethysmography for measurement of respiratory resistance in children with asthma or cystic fibrosis. Pediatr Pulmonol 2000;29:213-20.

18. Carter ER, Stecenko AA, Pollock BH,Jaeger MJ. Evaluation of the interrupter technique for the use of assessing airway obstruction in children. Pediatr Pulmonol 1994;17:211-7.

19. Pao CS, Healy MJ, McKenzie SA. Airway resistance by the interrupter technique: which algorithm for measur- ing pressure? Pediatr Pulmonol 2004;37:31-6.

20. Phagoo SB, Wilson NM, Silverman M. Evaluation of a new interrupter device for measuring bronchial responsiveness and the response to bronchodilator in 3 year old children. Eur Respir J 1996;9:1374-80.

21. Phagoo SB, Wilson NM, Silverman M. Evaluation of the interrupter technique for measuring change in airway resistance in 5-year-old asthmatic children. Pediatr Pulmonol 1995;20:387-95.

22. Beydon N, Trang-Pham H, Bernard A, Gaultier C. Measurements of resistance by the interrupter technique and of transcutaneous partial pressure of oxygen in young children during methacholine challenge. Pediatr Pulmonol 2001;31:238-46.

23. Gayrard P, Orehek J, Grimaud C, Charpin J. Bronchoconstrictor effects of a deep inspiration in patients with asthma. Am Rev Respir Dis 1975;111:433-9.

24. Prieto L, Lamarca R, Casado A. La evaluación de la fiabilidad en las observaciones clínicas: el coeficiente de correlación intraclase. Med Clin (Barc) 1998;110:142-5.

25. Bridge PD, Ranganathan S, McKenzie SA. Measurement of airway resistance using the interrupter technique in preschool children in the ambulatory setting. Eur Respir J 1999;13:792-6.

26. Klug B, Bisgaard H. Specific airway resistance, interrupter resistance, and respiratory impedance in healthy children aged 2-7 years. Pediatr Pulmonol 1998;25:322-31.

27. Adams AM, Olden C, Wertheim D, Ives A, et al. Measurement and repeatability of interrupter resistance in unsedated newborn infants. Pediatr Pulmonol 2009;44:1168-73.

28. Boukari R, Trang-Pham H, Bernard A, Grossi Y, Gaultier C. Variability of respiratory resistance measurements by the interruption technique in children. Am J Respir Crit Care Med 1997;155:A380.

29. Mele L, Sly PD, Calogero C, Bernardini R, et al. Assessment and validation of bronchodilation using the interrupter technique in preschool children. Pediatr Pulmonol 2010;45:633-8.

30. Bridge PD, McKenzie SA. Airway resistance measured by the interrupter technique: expiration or inspiration, mean or median? Eur Respir J 2001;17:495-8.

31. Chan EY, BridgePD, Dundas I,PaoCS, Healy MJ,McKenzie SA. Repeatability of airway resistance measurements made using the interrupter technique. Thorax 2003;58:344-7.

32. Beelen RM, Smit HA, van Strien RT, Koopman LP, et al. Short and long term variability of the interrupter technique under field and standardised conditions in 3-6 year old children. Thorax 2003;58:761-4.

33. Child F, Clayton S, Davies S, Fryer AA, et al. How should airways resistance be measured in young children: mask or mouthpiece? Eur Respir J 2001;17:1244-9.

34. Hadjikoumi I, Hassan A, Milner AD. Effects of respiratory timing and cheek support on resistance measurements, before and after bronchodilation in asthmatic children using the interrupter technique. Pediatr Pulmonol 2003;36:495501. 